\title{
Effecting Partial Elimination of Isocyanuric Acid from Swimming Pool Water Systems
}

\author{
Marina Corral Bobadilla ${ }^{1, *}$ (D) Eliseo P. Vergara González ${ }^{2}$, Rubén Lostado Lorza ${ }^{1}(\mathbb{D})$ and \\ Fátima Somovilla Gómez ${ }^{1}$ \\ 1 Department of Mechanical Engineering, University of La Rioja, 26004 Logroño, La Rioja, Spain; \\ ruben.lostado@unirioja.es (R.L.L.); fatima.somovilla@unirioja.es (F.S.G.) \\ 2 Department of Mining Exploitation and Prospecting, University of Oviedo, 33004 Oviedo, \\ Principality of Asturias, Spain; vergaraeliseo@uniovi.es \\ * Correspondence: marina.corral@unirioja.es; Tel.: +34-941-299-274
}

Received: 6 March 2019; Accepted: 3 April 2019; Published: 6 April 2019

\begin{abstract}
It is essential to disinfect the water in swimming pools in order to deactivate pathogenic microorganisms. Chlorination of swimming pool water provides rapid and long-lasting disinfection, but leads to the formation of potentially toxic compounds, including isocyanuric acid, that are used to stabilize chlorine in pool water. Hygiene and health guidelines require an isocyanuric acid concentration in swimming pools of 25 to $75 \mathrm{ppm}$ and that there be no level in excess of $100 \mathrm{ppm}$. This paper provides a new method to partially remove isocyanuric acid from the water of swimming pool systems with the use of melamine-based reagents. A melamine-photometry process stabilizes the isocyanuric acid. The melamine-based reagent that is added to the raw water reacts with the isocyanuric acid and forms a precipitated salt. The reaction also creates turbidity that is proportional to the isocyanuric acid concentration in the water. It was noted in this study that the optimum functioning range of melamine doses in the raw water was 0.04 to $0.06 \mathrm{~g} / \mathrm{L}$ and that the reduction of isocyanuric acid in raw water increased as the dose of melamine was increased. Thus, it is necessary to obtain an estimate of the dose of melamine that is necessary to reduce the isocyanuric acid in the water without needing to add fresh water from the network to dilute it. Finally, it can be stated that eliminating isocyanuric acid that has accumulated in a pool's water by treatment with melamine provides an efficient process, as it eliminates the amount of isocyanuric acid that is necessary to conform to the human health criteria of the European Union Directive 2006/7/EC. Treatment with melamine also reduces water network consumption and sewer discharge by successive purges that eventually will become unnecessary. Therefore, this proposed method is environmentally and economically beneficial.
\end{abstract}

Keywords: isocyanuric acid; water saving; melamine; chlorination; swimming pools systems; swimming pool water; THMs; disinfection byproduct

\section{Introduction}

Swimming is a popular aquatic activity that offers many health benefits. However, the quality of pool water is often compromised during busy periods. In fact, organic substances such as hair, skin particles, sunscreen, cosmetics, sweat and body fluids are brought into the water by swimmers unintentionally. These contaminate the water [1-5]. Therefore, to protect swimmers and others against infectious diseases, disinfecting the water of swimming pools is essential and maintaining the quality of the water should be a priority for owners and managers of swimming pools $[6,7]$.

Although a variety of disinfectants have been used for swimming pools, the most commonly employed method is chlorination [8-11]. It is intended to prevent disinfection of recreational water, 
the occurrence of waterborne diseases and inactivation of pathogenic micro-organisms. Chlorine is a chemical disinfectant, which is very effective and relatively inexpensive. Chlorine is dissolved in water or added as sodium hypochlorite $(\mathrm{NaOCl})$, calcium hypochlorite $\left(\mathrm{Ca}(\mathrm{OCl})_{2}\right)$ or another derivative, such as chloroisocyanurate [12]. One problem that is associated with the disinfection of water by chlorine products is the accumulation of potentially toxic disinfection byproducts in the pool [13-24]. Hypochlorous acid $(\mathrm{HOCl})$ is produced by adding active chlorine to water. $\mathrm{HOCl}$ is highly unstable and decomposes easily to form hydrochloric acid $(\mathrm{HCl})$, water and oxygen. In order to prolong the life of the active chlorine, an isocyanurate stabilizer is commonly added to the pool water. This prevents the usual and rapid dissipation of active chlorine by photochemical reactions due to ultraviolet radiation caused by direct exposure to sunlight. Ultraviolet radiation degrades the active chlorine, thereby changing the concentration of this compound in the water. The use of isocyanuric stabilizers eliminates this problem $[25,26]$. Figure 1 shows the residual active chlorine in the pool's water when an inorganic chlorinated derivative is used without a stabilizer in the disinfection process and the residual active chlorine when isocyanuric acid is used as a stabilizer.

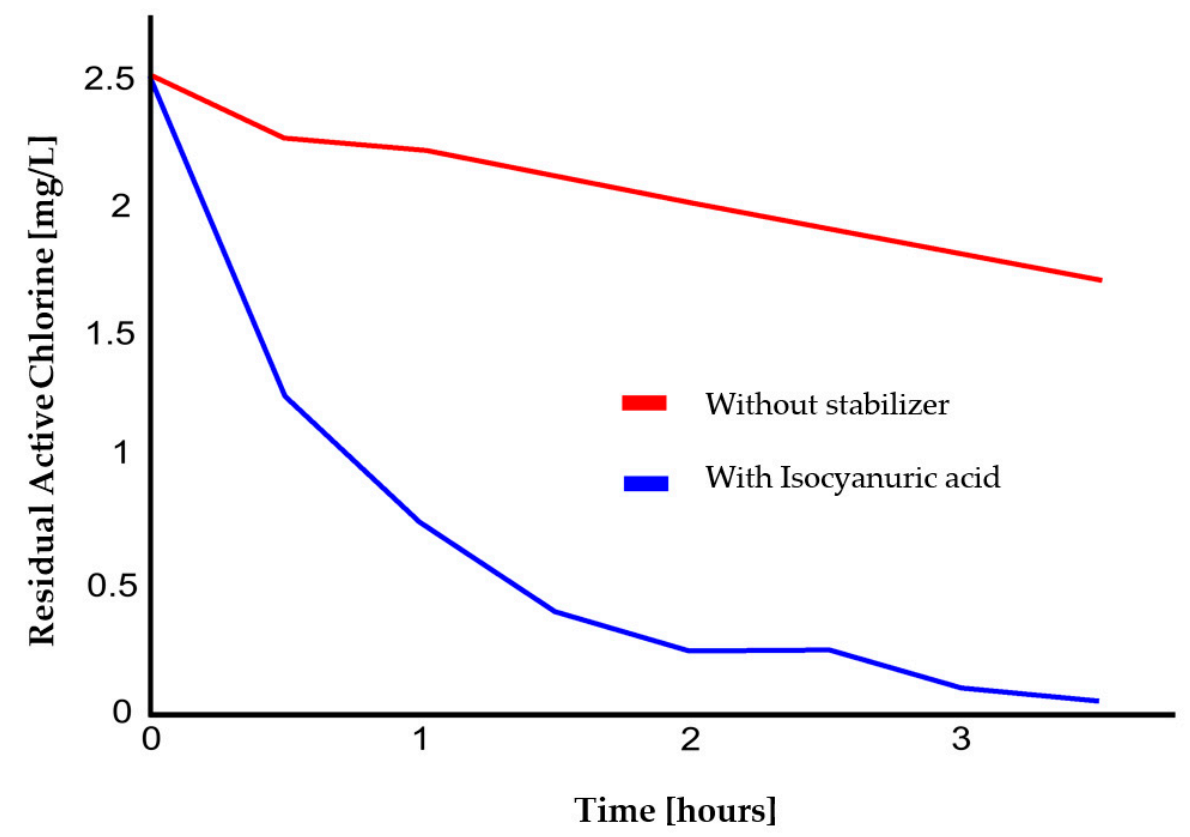

Figure 1. Comparison of residual active chlorine levels vs. the use of stabilizers (or lack thereof) [22].

Isocyanuric acid has received recognition for this ability but has also received the blame for over stabilization which reduces chlorine's effectiveness. This loss in effectiveness could possibly result in recreational water emerging diseases due to water quality standards being compromised. Thus, an isocyanuric acid level of $25-75 \mathrm{ppm}$ is recommended with an upper limit of $100 \mathrm{ppm}$ [27]. Thus, most health and hygiene regulations require a purge and daily renewal of $5 \%$ of fresh water in the pool to remove the excess isocyanuric acid. The fresh water is obtained from network water. The health departments and other regulators consider that high levels of isocyanuric acid can be harmful to health [28]. For example, in Spain, the RD 742/2013 [29] recommends that levels should not exceed $75 \mathrm{ppm}$. If the level exceeds $150 \mathrm{ppm}$, the pool will be closed until normalization of the value is achieved. In the USA, the Department of Health \& Human Services in the Model Aquatic Health Code, also recommend that the maximum concentration level of cyanuric acid be $100 \mathrm{ppm}$ [30]. In France, the use of isocyanuric acid is controlled, since the drainage and filling of swimming pools due to excessive isocyanuric acid is not allowed in so many regions because of water scarcity. The isocyanuric acid cannot be removed by conventional chemical treatment. It accumulates after weeks of treatment. Thus, the health and hygiene regulations require, to drain partially (5\%) the swimming pool with the influx of fresh water to re-establish the proper cyanuric acid limits. In order to reduce fresh water 
consumption and sewer discharge by successive purges that could become unnecessary, this paper proposes a methodology to remove the isocyanuric acid based on the addition of melamine. Melamine reacts with isocyanuric acid to form a precipitated salt and turbidity that is proportional to the concentration of isocyanuric acid present in the water. The chemical reaction between isocyanuric acid and melamine is shown in Figure 2.<smiles>Nc1nc(N)nc([NH2+])n1</smiles>

Figure 2. The insoluble complex that is formed by the reaction of isocyanuric acid and melamine.

To date, there are no previous studies in the literature that apply the effect of melamine on the elimination or neutralization of isocyanuric acid. In addition, there are no human studies on melamine toxicity, and the data of toxicity of melamine are limited to oral ingestion in animals and not by inhalation and dermal contact with pool water. Regarding the animal studies, to date indicate a low toxicity by oral ingestion. Melamine is not metabolized and is rapidly eliminated in the urine. Several reviews of the available information have been undertaken by the World Health Organization (WHO) [31,32]; the US Food and Drug Administration (US FDA) [33] and the European Food Safety Authority (EFSA) [34]. The US FDA has published an interim safety/risk assessment on melamine and structural analogues and has established a Tolerable Daily Intake (TDI) of melamine of $0.63 \mathrm{mg}$ per $\mathrm{kg}$ of body weight in humans. The EFSA has published a provisional statement and recommended that a TDI of $0.5 \mathrm{mg}$ per $\mathrm{kg}$ of body weight be adopted as tolerable daily intake value for melamine in humans. In this study, melamine is added during the purification process by a bypass which allows a dose of melamine to react with isocyanuric acid, filtering the precipitate formed before the water is returned to the pool [35]. In this way, the concentration of melamine in the pool water, if any, would be residual. Considering these statements, and due to the concentration of melamine used in this study for pool water is minimum, the harmful risk on human health of melamine can be considered as very low. The objective of this study was to develop a method to remove accumulated isocyanuric acid from the pool water in order to reduce the purged water and the consumption of network water, and to develop a low-cost scale system.

\section{Materials and Methods}

To determine if the process of removing the proposed isocyanuric acid is appropriate, the following steps were developed: First, in order to control the quality of the pool water, the level of isocyanuric acid was determined by adding melamine and employing the Melamine-Photometry method using sodium acetate and melamine as reagents. The reagent of reference standard $(2 \mathrm{~g} / \mathrm{L}$ melamine) was prepared by dissolving $3.5 \mathrm{~g}$ of sodium acetate and $0.2 \mathrm{~g}$ of melamine in several samples of $100 \mathrm{~mL}$ of fresh water. For isocyanuric acid analysis, it was necessary to homogenize the water sample, and then transfer a $10 \mathrm{~mL}$ of it to a test tube. This $10 \mathrm{~mL}$ of water sample was mixed with $5 \mathrm{~mL}$ of prepared reagent. The resulting turbidity was measured in the spectrophotometer at $\lambda=525 \mathrm{~nm}$ using a $50 \mathrm{~mm}$ quartz cuvette. Finally, the precipitate that formed was removed using a filter of $0.45 \mu \mathrm{m}$ pore size, and the absorbance of the clarified water was measured. The concentration of isocyanuric acid was determined by the difference between the total absorbance obtained in the water sample after complexation and filtration. The spectrophotometric measurements to determine the concentration of isocyanuric acid based on atomic absorption, were carried out on a Unicam Helios $\alpha$ model spectrophotometer (Unicam, Cambridge, UK). The turbidity measurement was conducted 
with a 2100Q Turbidimeter (Hach Company, Loveland, CO, USA) according to the ASTM D1889-00 standard [36], and Total Suspended Solids following the standard ASTM D5907-10 method [37]. The $\mathrm{pH}$ and the $\mathrm{CE}$ of the solutions were measured with a Multi-parameter MultiLine 3630 IDS (WTW, Weilheim, Germany) following the ASTM D1293-18 [38] and ASTM D1125-14 [39] standards respectively. After determining the isocyanuric acid concentration, the correlation between isocyanuric acid and melamine was determined by the following procedure:

Since it was not possible to have real pool water that contain a predetermined concentration of isocyanuric acid to study the repeatability of the isocyanuric acid determination method, a synthetic solution with a known isocyanuric acid loading was prepared in the laboratory. The melamine-photometry method was applied again on this synthetic solution. These synthetic samples were prepared by dissolving $0.05 \mathrm{~g}$ of isocyanuric acid in $500 \mathrm{~mL}$ of tap water that had a temperature between $10^{\circ}$ and $20^{\circ}$ and a $\mathrm{pH}$ between 7.2 and 7.5. Subsequently the samples were shaken vigorously for $20 \mathrm{~min}$ using a magnetic plate stirrer. Finally, the isocyanuric acid content was analyzed to verify that the concentration of the solution sample was what was sought. The different doses of the melamine prepared reagent were added to the samples in the jar test. The jar test that was used in the experiments involved a programmable apparatus (FLOCUMATIC, Selecta, Spain [40]). This apparatus consisted of six paddles on a bench. The paddles were connected to each other by a gear mechanism, and were rotated simultaneously by the same motor at a controlled speed (200 rpm) and for a specified time $(10 \mathrm{~min})$. Water samples were transferred to the jars. Then, a different dose of the melamine prepared reagent $(0-1 \mathrm{~g} / \mathrm{L})$ was added to each beaker. After rapid stirring, the homogeneous sample was filtered by a glass fiber filter $(0.45 \mu \mathrm{m})$. After each sample had been filtered, the water was analyzed to determine the isocyanuric acid present in the resulting liquid. At this stage, it was important to calculate the efficiency of the method in removing the isocyanuric acid and to quantify the performance by the amount of reagent (melamine) added. Comparing the efficiency of the method of removal efficiency to the isocyanuric acid parameter is described by the following:

$$
\mathrm{E}=\left[\left(\mathrm{ICN}_{\mathrm{I}}-\mathrm{ICN}_{\mathrm{F}}\right) / \mathrm{ICN}_{\mathrm{I}}\right] \times 100
$$

where:

$\mathrm{E}=$ isocyanuric acid removal efficiency (\%)

$\mathrm{ICN}_{\mathrm{I}}=$ isocyanuric acid concentration in raw water $(\mathrm{mg} / \mathrm{L})$

$\mathrm{ICN}_{\mathrm{F}}=$ isocyanuric acid residual concentration in the filtered water $(\mathrm{mg} / \mathrm{L})$.

The last step of the proposed procedure consisted of filtering the insoluble complex isocyanuric acid-melamine. In this stage, the insoluble complex, isocyanuric acid-melamine, was removed by filtration. The filter used in this case was a Silex filter. These filter elements are used in majority of water purification installations for swimming pools mainly due to their ease of use.

\section{Results and Discussion}

The removal of isocyanuric acid was investigated by an experimental design procedure. The experimental results of the different steps of the new system for isocyanuric acid removal are presented in the following pages.

\subsection{Results of the Repeatability of the Melamine-Photometry Process}

This section provides the repeatability test results of the melamine-photometry process by which, the spectrophotometer and the correlation between isocyanuric acid and melamine, the amount of isocyanuric acid in water samples was determined. In the process of melamine-photometry, the repeatability of the quantitative results is of key importance. Figure 3 shows the linear correlation $\left(R^{2}=0.93\right)$ in the two different essays of the analytic method that were conducted with two different spectrophotometers. From the analysis, it can be deduced that the error is very acceptable for this type 
of tests and permits us to conclude that the analysis of isocyanuric acid by adding melamine method is very reliable.

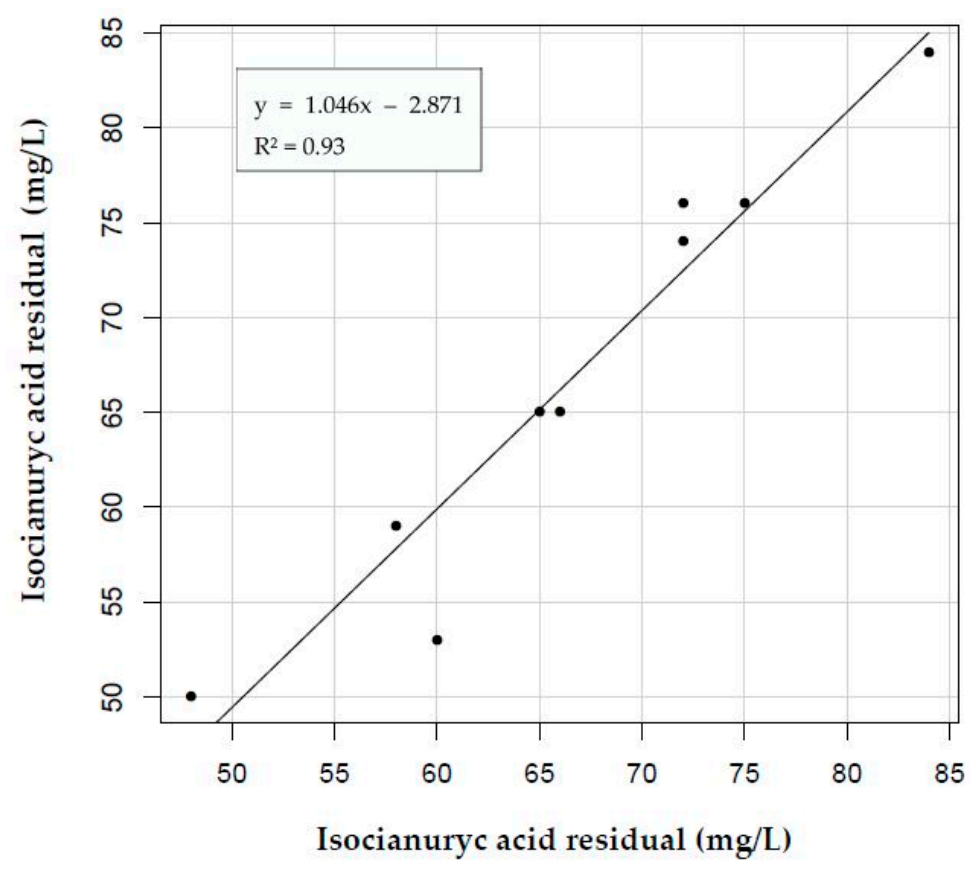

Figure 3. Linear correlation of the two methods studied.

\subsection{The Efficiency Achieved in Eliminating Isocyanuric Acid from Sample Water}

The isocyanuric acid removal efficiency was checked in the first series of tests, by adding melamine (0-1 g/L) to the raw water (synthetic solution). Figure 4 shows the amount of residual isocyanuric acid in the water after adding melamine and subsequently filtering the water (lower line) versus adding melamine and no filtration (upper line). Figure 4 shows that the addition of $0.3 \mathrm{~g} / \mathrm{L}$ of melamine resulted in the removal of $98 \%$ (practically all) of the insoluble isocyanuric acid-melamine complex.

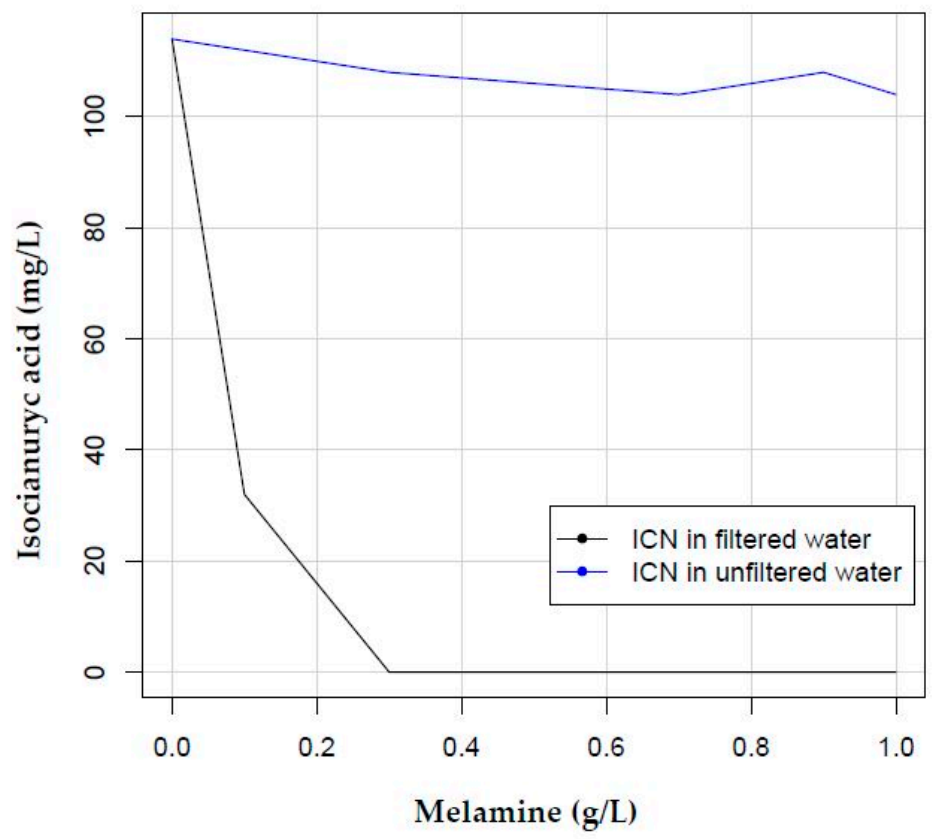

Figure 4. Variation of isocyanuric acid residual in the filtered water vs. adding melamine $(0-1 \mathrm{~g} / \mathrm{L})$. 
Figure 5a shows the results obtained after another series of trials were conducted to narrow the range of melamine addition and optimize its consumption (melamine doses between 0.02 to $0.08 \mathrm{~g} / \mathrm{L}$ ). Figure $5 \mathrm{a}$ shows that the correlation coefficient is 0.97 . This means that there is an almost linear relationship between the residual and the melamine isocyanuric acid that is added. Similarly, isocyanuric acid concentration varies inversely to the dose of melamine. This inverse relationship can be calculated by Equation (2).

$$
\operatorname{ICN}(\mathrm{mg} / \mathrm{L})=-1103.6 \times \mathrm{M}(\mathrm{g} / \mathrm{L})+116.89
$$

where:

$\mathrm{ICN}=$ isocyanuric acid concentration $(\mathrm{mg} / \mathrm{L})$

$\mathrm{M}=$ melamine dose $(\mathrm{g} / \mathrm{L})$.

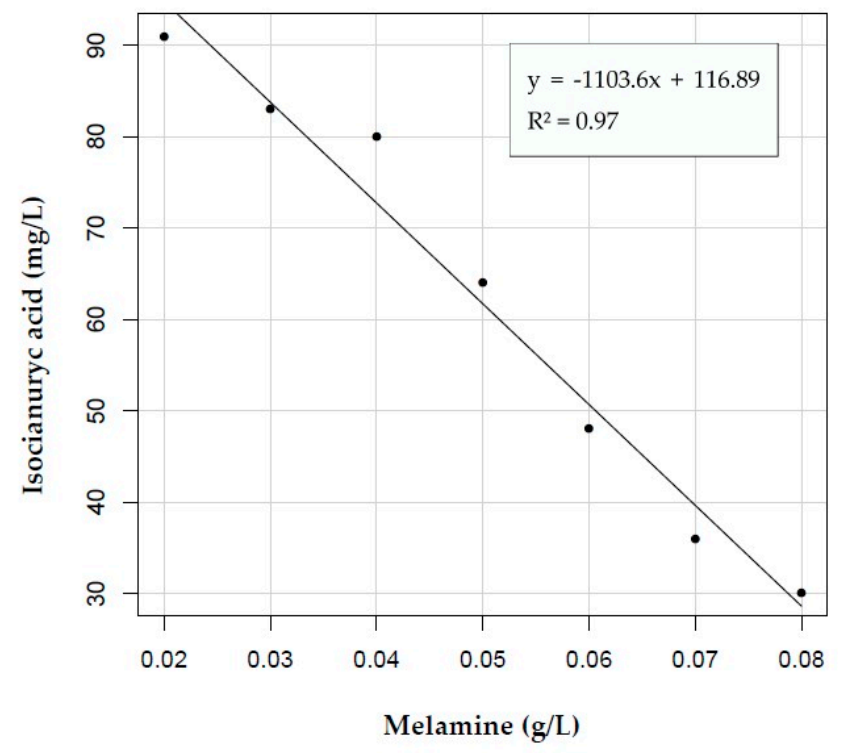

(a)

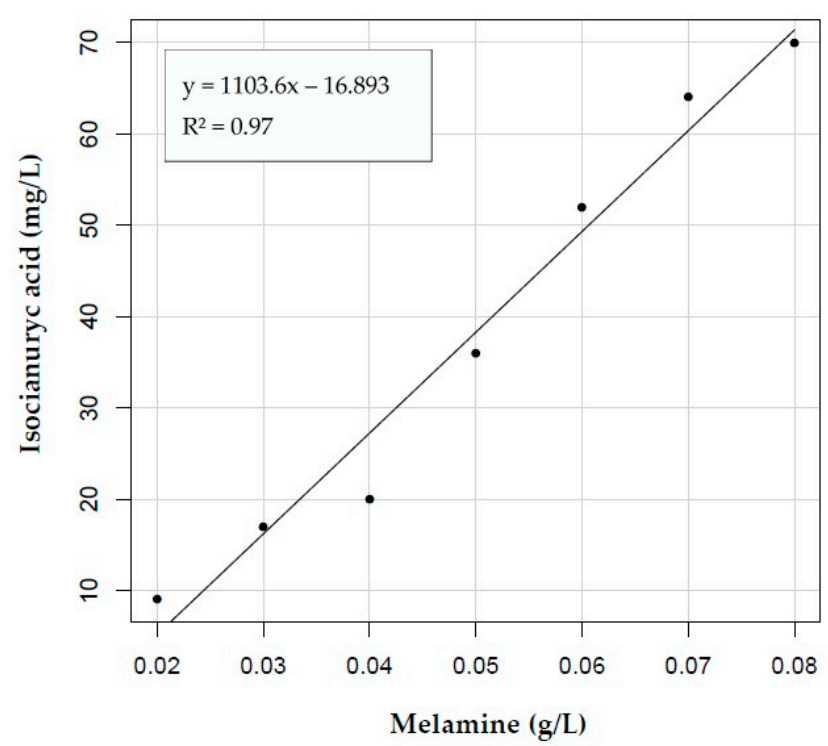

(b)

Figure 5. Range of melamine additions $(0.02-0.08 \mathrm{~g} / \mathrm{L})$ : (a) Variation of isocyanuric acid residual in the filtered water, (b) variation of isocyanuric acid removed in the filtered water. 
When the concentration of isocyanuric acid in the raw water and the filtered water is known, the isocyanuric acid that was removed in the physical-chemical treatment can be calculated and, also, the efficiency of the same. Figure $5 \mathrm{~b}$ shows the evolution of residual isocyanuric acid that was removed from the water sample after melamine was added, and the water was filtered. In this case, the dose of melamine that was added was between 0.02 and $0.08 \mathrm{~g} / \mathrm{L}$. It was noted that the addition of $0.02 \mathrm{~g} / \mathrm{L}$ of melamine produced an isocyanuric acid removal of $9 \%$ on average, whereas a dose of $0.08 \mathrm{~g} / \mathrm{L}$, decreased by $70 \%$ the presence of the isocyanuric acid in water.

Considering that the amount to be removed in the sample water should be between $20 \%$ and $50 \%$ of isocyanuric acid, further tests were conducted at lower doses $(0.04$ to $0.06 \mathrm{~g} / \mathrm{L})$ of melamine. These appear in Figure $6 \mathrm{a}, \mathrm{b}$ respectively. Figure 6a shows an average concentration of 80 to $48 \mathrm{mg} / \mathrm{L}$ of residual isocyanuric acid in the filtered water, after an addition of 0.04 and $0.06 \mathrm{~g} / \mathrm{L}$ of melamine, respectively.

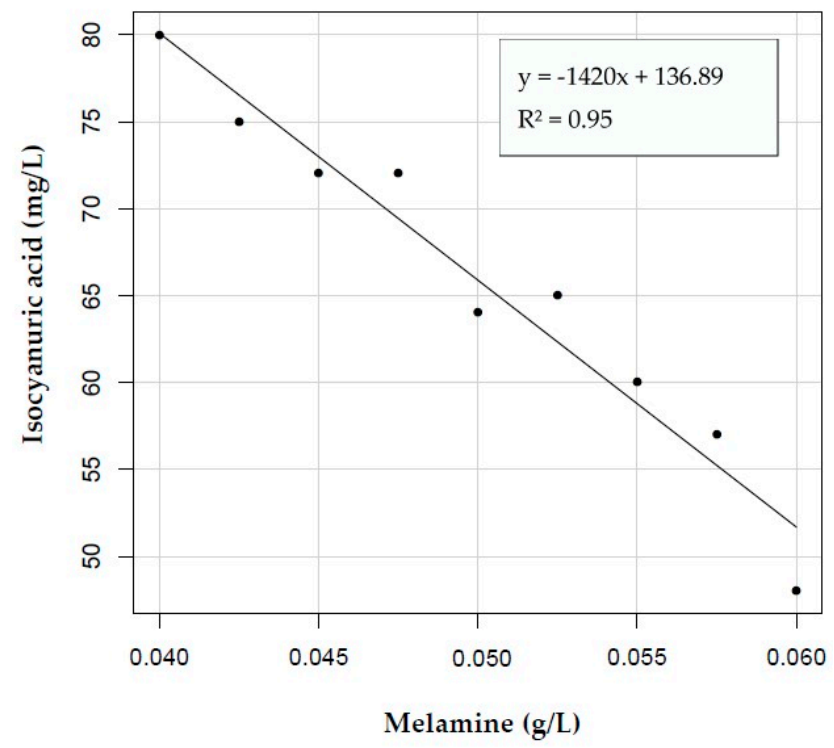

(a)

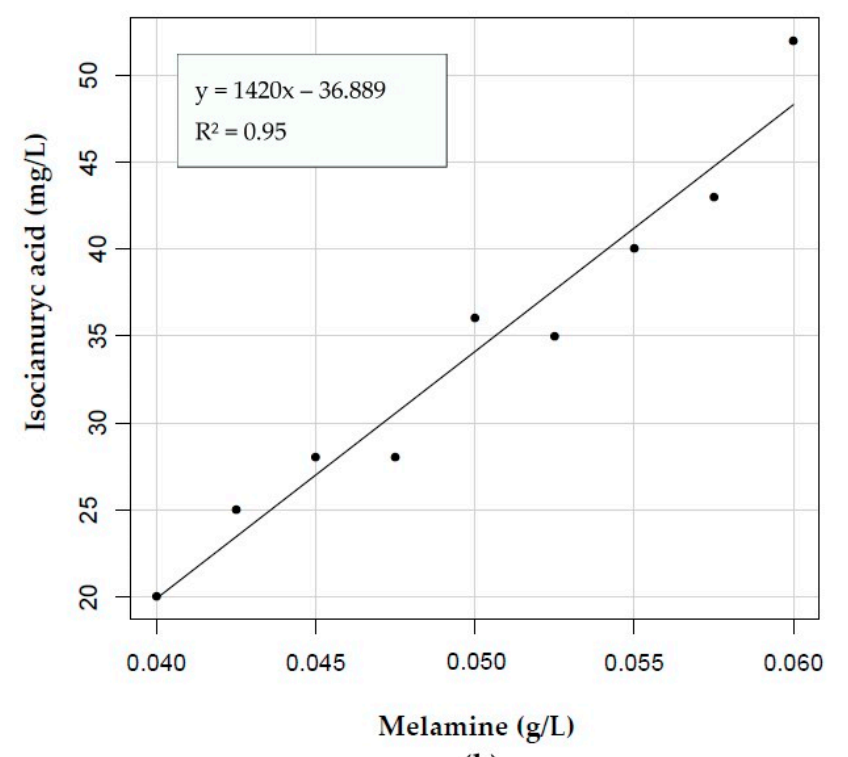

(b)

Figure 6. Range of doses of addition of melamine (0.04-0.06 g/L): (a) Variation of isocyanuric acid residual in the filtered water; (b) variation of isocyanuric acid removed in the filtered water. 
Similarly, Figure $6 \mathrm{~b}$ shows that, as the efficiency of isocyanuric acid removal increased by adding more melamine. It also shows that the average percentage of removal of isocyanuric acid was $16 \%$ for $0.04 \mathrm{~g} / \mathrm{L}$ and $52 \%$ for the higher dose of $0.06 \mathrm{~g} / \mathrm{L}$.

All of these data led to the conclusion that the optimum working range of doses of melamine in the raw water was between 0.04 and $0.06 \mathrm{~g} / \mathrm{L}$, with the reduction of isocyanuric acid in the initial water increasing as the dose is increased. This stage of the study facilitated verification of the method based on the addition of melamine to determine isocyanuric acid. It was also noted that the socyanuric acid-melamine complex could be removed by filtration. As a result, one can estimate the melamine dose that is necessary to reduce the isocyanuric acid of the water without a need to add tap water.

\subsection{Results of the Repeatability of the Linear Correlation of Isocyanuric Acid-Melamine}

The results of the study of repeatability and reproducibility of the linear correlation isocyanuric acid-melamine are described next. In order to verify the linear relationship obtained in the above results, the reduction of $20 \mathrm{mg} / \mathrm{L}$ of initial water, isocyanuric acid containing isocyanuric acid ranging from 20 to $100 \mathrm{mg} / \mathrm{L}$ was included in the study. For this reason, a constant dose of $0.04 \mathrm{~g} / \mathrm{L}$ melamine was added to each of the samples synthesized. The addition of a dose of $0.04 \mathrm{~g} / \mathrm{L}$ of melamine obtained an average value of removal of $22 \mathrm{mg} / \mathrm{L}$ of isocyanuric acid (Figure 7). These values confirm a high repeatability of the conducted measurements. These results coincide with those of the previous tests.

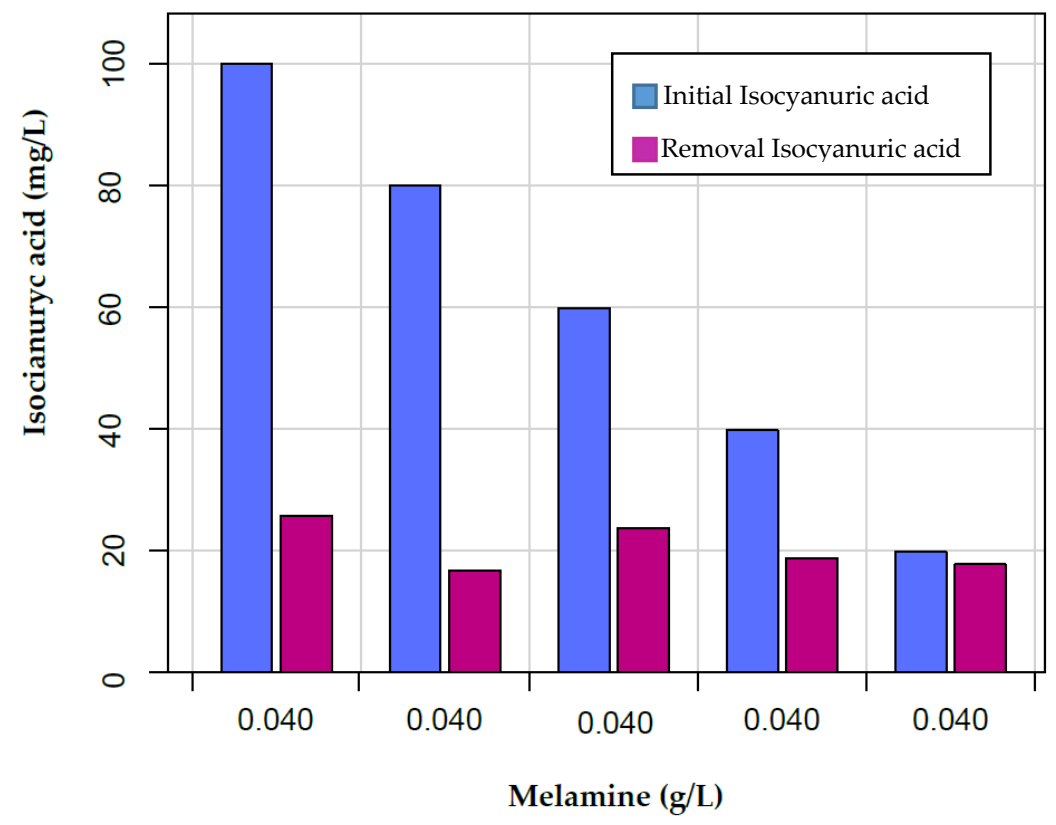

Figure 7. Variation of isocyanuric acid removed in the filtered water versus the addition of $0.04 \mathrm{~g} / \mathrm{L}$ of melamine.

Table 1 summarizes the results of this test, the standard deviation and the mean value of isocyanuric acid that was eliminated. The tests involved adding $0.04 \mathrm{~g} / \mathrm{L}$ of melamine to different water samples that contained isocyanuric acid between 20 and $100 \mathrm{mg} / \mathrm{L}$. The accuracy of the results from the analytical method was very good. The repeatability of the results measured as the deviation was satisfactory; its value was 4 . 
Table 1. Results of isocyanuric acid after addition of a constant dose of melamine and removal of isocyanuric acid.

\begin{tabular}{cccc}
\hline $\begin{array}{c}\text { Melamine Dose } \\
(\mathbf{g} / \mathbf{L})\end{array}$ & $\begin{array}{c}\text { Isocyanuric Acid Initial } \\
(\mathbf{m g} / \mathbf{L})\end{array}$ & $\begin{array}{c}\text { Isocyanuric Acid Residual } \\
(\mathbf{m g} / \mathbf{L})\end{array}$ & $\begin{array}{c}\text { Isocyanuric Acid Removed } \\
(\mathbf{m g} / \mathbf{L})\end{array}$ \\
\hline 0.04 & 100 & 74 & 26 \\
0.04 & 80 & 63 & 17 \\
0.04 & 60 & 36 & 24 \\
0.04 & 40 & 21 & 19 \\
0.04 & 20 & 2 & 18 \\
0.04 & 100 & 69 & 31 \\
0.04 & 80 & 59 & 21 \\
0.04 & 60 & 35 & 25 \\
0.04 & 40 & 21 & 19 \\
0.04 & 20 & 1 & 19 \\
\hline
\end{tabular}

\subsection{Filtering Results of Insoluble Complex Isocyanuric Acid-Melamine}

The complexation of isocyanuric acid with melamine produces an insoluble complex isocyanuric acid-melamine, which is in the form of microscopic crystals that are suspended in water. In the last stage of the study, these microscopic crystals that are suspended in water were removed by Silex filtration filters, which act as natural filtering agents.

Figure 8 shows the percentage of isocyanuric acid removed by particle size of the filter medium. From Figure 8, it is deducted that increasing the grain size of the sand decreases the isocyanuric acid removal rate, because the filter with lower granulometry of $0.4-0.8 \mathrm{~mm}$ is the most efficient as it removes $50 \%$ of the isocyanuric acid in the water samples. Filters of Silex sand with reduced granulometry $(0.1-0.3 \mathrm{~mm})$ produced a better quality of filtered water. This resulted in both a greater number of washes and cleaning of the hardest filters. In turn, this increased the expense of the isocyanuric acid removal process.

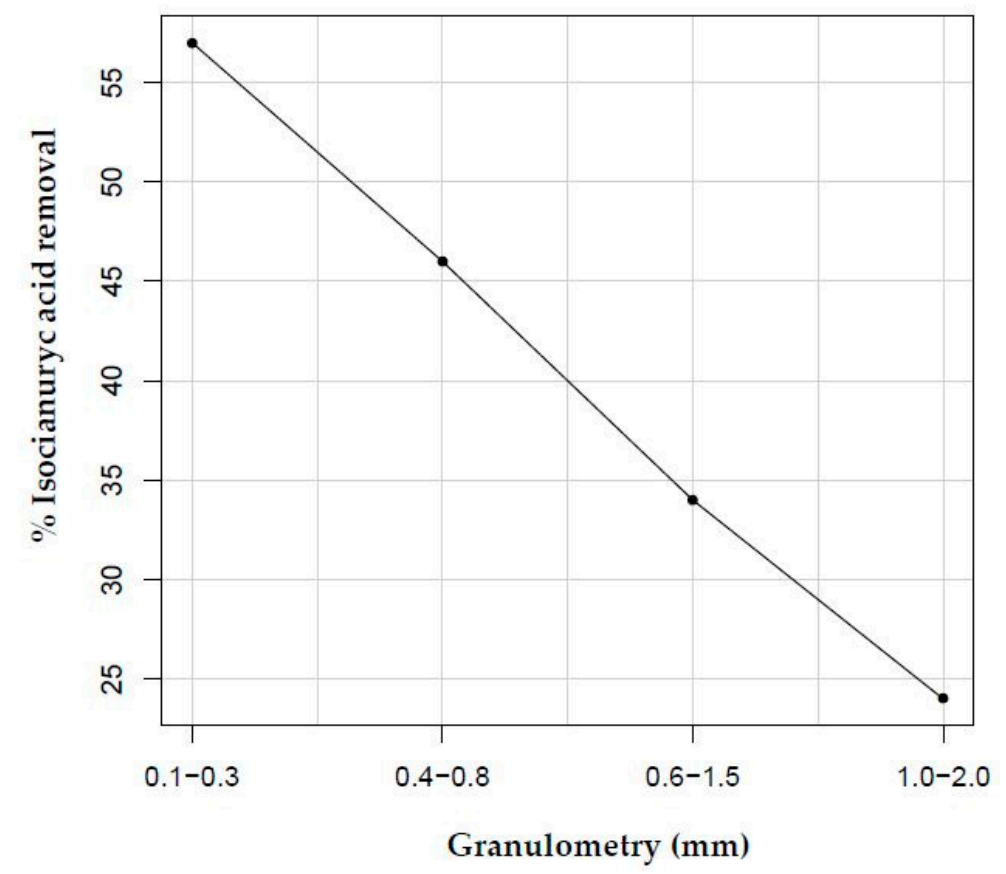

Figure 8. Isocyanuric acid removal rate vs. particle size of the filter medium tested. 


\section{Conclusions}

A methodology for removal of isocyanuric acid in swimming pool water is presented in this paper. The development process can be used to control isocyanuric acid in swimming pool water that cannot be removed by conventional pool water treatment. Thus, dilution with fresh water is necessary to keep the cyanuric acid at an acceptable concentration.

Chlorination of swimming pool water provides rapid and long-lasting disinfection, but leads to the formation of potentially toxic compounds, including isocyanuric acid, that are used to stabilize chlorine in pool water. The treatment requires draining $5 \%$ of the water from the pool to eliminate the isocyanuric acid that has accumulated, in compliance with the European Union Directive 2006/7/EC [41]. The proposed method, Melamine-photometry, allows the partial removal of the isocyanuric acid that has accumulated in the water of the pool. The process involves the removal of isocyanuric acid by a melamine-based reagent. The melamine reacts with isocyanuric acid in a process that offers satisfactory repeatability and accuracy, forming an insoluble complex that is easy to remove by filtration. It was found in this study that the optimum functioning range of melamine doses in raw pool water was 0.04 to $0.06 \mathrm{~g} / \mathrm{L}$ and that the reduction of isocyanuric acid in the raw water increased as the dose increased. Thus, an estimate of the dose of melamine that is necessary to reduce the concentration of isocyanuric acid in the water has been obtained without needing to add water to the network. In summary, the removal of accumulated isocyanuric acid by a chemical treatment that uses melamine has become economically and environmentally beneficial. It reduces water network consumption, as well as sewer discharge, by successive purges that eventually will be unnecessary.

Author Contributions: Experimental work: M.C.B., E.P.V.G., R.L.L. and F.S.G. Results analysis, revision and improvement of the manuscript: All authors.

Funding: This research received no external funding.

Conflicts of Interest: The authors declare no conflict of interest.

\section{References}

1. Sakkas, V.A.; Giokas, D.L.; Lambropoulou, D.A.; Albanis, T.A. Aqueous photolysis of the sunscreen agent octyldimethyl- $p$-aminobenzoic acid formation of disinfection byproducts in chlorinated swimming pool water. J. Chromatogr. A 2003, 1016, 211-222. [CrossRef]

2. Kanan, A.; Karanfil, T. Formation of disinfection by-products in indoor swimming pool water: The contribution from filling water natural organic matter and swimmer body fluids. Water Res. 2011, 45, 926-932. [CrossRef] [PubMed]

3. Hang, C.; Zhang, B.; Gong, T.; Xian, Q. Occurrence and health risk assessment of halogenated disinfection byproducts in indoor swimming pool water. Sci. Total Environ. 2016, 543, 425-431. [CrossRef] [PubMed]

4. Keuten, M.G.A.; Schets, F.M.; Schijven, J.F.; Verberk, J.Q.; Van Dijk, J.C. Definition and quantification of initial anthropogenic pollutant release in swimming pools. Water Res. 2012, 46, 3682-3692. [CrossRef] [PubMed]

5. Schmalz, C.; Frimmel, F.H.; Zwiener, C. Trichloramine in swimming pools-Formation and mass transfer. Water Res. 2011, 45, 2681-2690. [CrossRef] [PubMed]

6. Valeriani, F.; Protano, C.; Vitali, M.; Romano Spica, V. Swimming attendance during childhood and development of asthma: Meta-analysis. Pediatr. Int. 2017, 59, 614-621. [CrossRef]

7. Announcement: Healthy and Safe Swimming Week-May 23-29, 2016. MMWR Morb. Mortal. Wkly. Rep. 2016, 65, 500. Available online: https://www.cdc.gov/mmwr/volumes/65/wr/mm6519a4.htm (accessed on 29 March 2019). [CrossRef] [PubMed]

8. World Health Organization (WHO). Guidelines for Safe Recreational Water Environments; Swimming Pools and Similar Environments; WHO Press: Geneva, Switzerland, 2006; Volume 2. Available online: http:/ /apps.who. int/iris/bitstream/10665/43336/1/9241546808_eng.pdf (accessed on 29 May 2018).

9. Chowdhury, S.; Alhooshani, K.; Karanfil, T. Disinfection by-products in swimming pool: Occurrences, implications and future needs. Water Res. 2014, 53, 68-109. [CrossRef] [PubMed]

10. Teo, T.L.L.; Coleman, H.M.; Khan, S.J. Chemical contaminants in swimming pools: Occurrence, implications and control. Environ. Int. 2015, 76, 16-31. [CrossRef] [PubMed] 
11. Ilyas, H.; Masih, I.; Van der Hoek, J. Disinfection methods for swimming pool water: Byproduct formation and control. Water 2018, 10, 797. [CrossRef]

12. Dychdla, G.R. Chlorine and Chlorine Compounds; Lea and Febiger: Philadelfia, PA, USA, 1991.

13. Lempart, A.; Kudlek, E.; Dudziak, M. Determination of Micropollutants in Water Samples from Swimming Pool Systems. Water 2018, 10, 1083. [CrossRef]

14. Daiber, E.J.; DeMarini, D.M.; Ravuri, S.A.; Liberatore, H.K.; Cuthbertson, A.A.; Thompson-Klemish, A.; Byer, J.D.; Schmid, J.E.; Afifi, M.Z.; Blatchley, E.R. Progressive increase in disinfection byproducts and mutagenicity from source to tap to swimming pool and spa water: Impact of human inputs. Environ. Sci. Technol. 2016, 50, 6652-6662. [CrossRef] [PubMed]

15. Jacobs, J.H.; Spaan, S.; Van Rooy, G.B.; Meliefste, C.; Zaat, V.A.; Rooyackers, J.M.; Heederik, D. Exposure to trichloramine and respiratory symptoms in indoor swimming pool workers. Eur. Respir. J. 2007, 29, 690-698. [CrossRef]

16. Zwiener, C.; Richardson, S.D.; De Marini, D.M.; Grummt, T.; Glauner, T.; Frimmel, F.H. Drowning in disinfection byproducts? Assessing swimming pool water. Environ. Sci. Technol. 2007, 41, 363-372. [CrossRef]

17. Weaver, W.A.; Li, J.; Wen, Y.; Johnston, J.; Blatchley, M.R.; Blatchley, E.R., III. Volatile disinfection by-product analysis from chlorinated indoor swimming pools. Water Res. 2009, 43, 3308-3318. [CrossRef]

18. Lee, J.; Jun, M.J.; Lee, M.H.; Lee, M.H.; Eom, S.W.; Zoh, K.D. Production of various disinfection byproducts in indoor swimming pool waters treated with different disinfection methods. Int. J. Hyg. Environ. Health 2010, 213, 465-474. [CrossRef]

19. Manasfi, T.; Méo, M.D.; Coulomb, B.; Giorgio, C.D.; Boudenne, J.L. Identification of disinfection by-products in freshwater and seawater swimming pools and evaluation of genotoxicity. Environ. Int. 2016, 88, 94-102. [CrossRef]

20. Pinto, G.; Rohrig, B. Use of chloroisocyanurates for disinfection of water. J. Chem. Educ. 2003, 80, 41-44. [CrossRef]

21. Yan, M.; Roccaro, P.; Fabbricino, M.; Korshin, G.V. Comparison of the effects of chloramine and chlorine on the aromaticity of dissolved organic matter and yields of disinfection by-products. Chemosphere 2018, 191, 477-484. [CrossRef] [PubMed]

22. Sun, X.; Wei, D.; Liu, W.; Geng, J.; Liu, J.; Du, Y. Formation of novel disinfection by-products chlorinated benzoquinone, phenyl benzoquinones and polycyclic aromatic hydrocarbons during chlorination treatment on UV filter 2, 4-dihydroxybenzophenone in swimming pool water. J. Hazard. Mater. 2019, 367, 725-733. [CrossRef]

23. Van Veldhoven, K.; Keski-Rahkonen, P.; Barupal, D.K.; Villanueva, C.M.; Font-Ribera, L.; Scalbert, A.; Bodinier, B.; Grimalt, J.O.; Zwiener, C.; Vlaanderen, J.; et al. Effects of exposure to water disinfection by-products in a swimming pool: A metabolome-wide association study. Environ. Int. 2018, 111, 60-70. [CrossRef] [PubMed]

24. Villanueva, C.M.; Cantor, K.P.; Grimalt, J.O.; Malats, N.; Silverman, D.; Tardon, A.; Garcia-Closas, R.; Serra, C.; Carrato, A.; Catano-Vinyals, G.; et al. Bladder cancer and exposure to water disinfection by-products through ingestion, bathing, showering, and swimming in pools. Am. J. Epidemiol. 2007, 156, 148-156. [CrossRef] [PubMed]

25. Taylor Technologies, Inc. Pool and Spa Water Chemistry: A Testing and Treatment Guide Waterproof Edition; Taylor Technologies Inc.: Sparks, NV, USA, 2011.

26. Canelli, E. Chemical, bacteriological, and toxicological properties of cyanuric acid and chlorinated isocyanurates as applied to swimming pool disinfection: A review. Am. J. Public Health 1974, 64, 155-162. [CrossRef] [PubMed]

27. De Macedo, J.A. O estado da arte da relação ácido cianúrico e superestabilização. Revista Controle da Contaminação 2003, 6, 32-38.

28. Dufour, A.; Evans, O.; Behymer, T.; Cantu, R. Water ingestion during swimming activities in a pool: A pilot study. J Water Health 2006, 4, 425-430. [CrossRef] [PubMed]

29. Royal Decree 742/2013, of 27 September, Establishing the Technical and Health Criteria Established Pools; Núm. 244; Official State Bulletin of Government of Spain: La Rioja, Spain, 2013; pp. 83123-83135.

30. Model Aquatic Health Code (MAHC). U.S. Department of Health \& Human Services. Available online: https:/ / www.cdc.gov/mahc/pdf/2018-MAHC-Code-Clean-508.pdf (accessed on 27 March 2019). 
31. World Health Organization (WHO). Toxicological and Health Aspects of Melamine and Cyanuric Acid: Report of a WHO Expert Meeting in Collaboration with FAO, Supported by Health Canada, Ottawa, Canada, 1-4 December 2008. 2009. Available online: https:/ /www.who.int/foodsafety/publications/chem/ Melamine_report09.pdf (accessed on 27 March 2019).

32. World Health Organization (WHO). Melamine and Cyanuric Acid: Toxicity, Preliminary Risk Assessment and Guidance on Levels in Food. 25 September 2008. Available online: https:/ / www.who.int/foodsafety/ fs_management/Melamine.pdf (accessed on 27 March 2019).

33. US Food and Drug Administration (US, FDA). Interim Melamine and Analogues Safety/Risk Assessment; United States Food and Drug Administration, Center for Food Safety and Applied Nutrition: Washington, DC, USA, 2007.

34. European Food Safety Authority (EFSA). Concise European Food Consumption Database. Parma. 2008. Available online: https:/ / www.efsa.europa.eu/en/food-consumption/comprehensive-database (accessed on 27 March 2019).

35. González, A.; Martínez-de-Pisón, F.J.; Vergara, E.P.; Alba, F.; Fernández, R.; Pernía, A.V. Método y dispositivo para la eliminación parcial del ácido isocianúrico en el agua de piscinas. Patent No. 2336185, 20 January 2011.

36. ASTM D1889-00 Standard Test Method for Turbidity of Water (Withdrawn 2007). Available online: https:/ / www.astm.org/Standards/D1889.htm (accessed on 10 September 2018).

37. ASTM D5907-10 Standard Test Methods for Filterable Matter (Total Dissolved Solids) and Nonfilterable Matter (Total Suspended Solids) in Water. Available online: https:/ /www.astm.org/Standards/D5907.htm (accessed on 15 September 2018).

38. ASTM D1293-18 Standard Test Methods for pH of Water. Available online: https://www.astm.org/ Standards/D1293.htm (accessed on 17 September 2018).

39. ASTM D1125-14 Standard Test Methods for Electrical Conductivity and Resistivity of Water. Available online: https: / /www.astm.org/Standards/D1125.htm (accessed on 17 September 2018).

40. Available online: http://www.gruposelecta.com/es/catalogo/subcategorias/5/AGITADORES (accessed on 17 September 2018).

41. Directive 2006/7 /EC of the European Parliament and of the Council of 15 February 2006 Concerning the Management of Bathing Water Quality. Available online: https://eur-lex.europa.eu/eli/dir/2006/7/oj (accessed on 9 May 2018).

(C) 2019 by the authors. Licensee MDPI, Basel, Switzerland. This article is an open access article distributed under the terms and conditions of the Creative Commons Attribution (CC BY) license (http://creativecommons.org/licenses/by/4.0/). 